\title{
Mechanical Prophylaxis of Venous Thrombosis in Patients Undergoing Craniotomy: A Randomized Trial
}

\author{
Michael N. Bucci, M.D., Stephen M. Papadopoulos, M.D., James C. Chen, M.D., \\ John A. Campbell, B.A., and Julian T. Hoff, M.D. \\ Section of Neurosurgery, University of Michigan, Ann Arbor, Michigan
}

Bucci MN, Papadopoulos SM, Chen JC, Campbell JA, Hoff JT. Mechanical prophylaxis of venous thrombosis in patients undergoing craniotomy: a randomized trial. Surg Neurol $1989 ; 32: 285-8$.

A randomized, prospective clinical trial of 70 patients undergoing craniotomy was performed to compare and evaluate two forms of mechanical prophylaxis of deep vein thrombosis. Thirty-eight patients received antiembolism stockings, whereas 32 patients received external pneumatic compression. Prophylaxis was begun preoperatively and continued intraoperatively and postoperatively until the patients were ambulatory. Impedance plethysmography was used to detect deep vein thrombosis both preoperatively and postoperatively. Two patients, one from each group, developed thromboembolic complications postoperatively. Impedance plethysmography showed false-positive findings in two additional patients. There were no deaths. The data suggest that either form of mechanical prophylaxis is effective against the development of deep vein thrombosis in this high-risk patient population.

KEY WORDS: Antiembolism stockings; Deep vein thrombosis; External pneumatic compression; Impedance plethysmography

Despite the recent advances in the treatment of neurosurgical disorders, the prevention of thromboembolism in the postoperative patient remains challenging. The incidence of deep venous thrombosis (DVT) in this group of patients has been reported to be as high as $29 \%$ and $43 \%[14,28]$.

Various pharmacological and mechanical methods have been used in the prevention of DVT [2-4,6$8,10,13,15-19,22,24,27]$. Although the methods dif-

Address reprint requests 10 : Michael N. Bucci, M.D., University of Michigan, Taubman Health Care Center, 1500 E. Medical Center Drive, Ann Arbor, Michigan 48109-0338.

Received February 6, 1989; accepted May 19, 1989. fer, the data indicate that prophylaxis reduces the incidence of DVT in the high-risk patient when compared to that in controls.

The detection of DVT includes both invasive and noninvasive methods such as ${ }^{125}$ I-fibrinogen scanning, impedance plethysmography (IPG), Doppler ultrasonography, and venography; however, the accuracy of each remains controversial $[11,12,23]$. Clinical evaluation alone, however, appears to be unreliable as many patients harbor silent DVT [21,25].

This study examines the efficacy of mechanical prophylaxis of DVT in a high-risk neurosurgical patient population.

\section{Materials and Methods}

Between November 1985 and April 1987, 70 adult patients undergoing craniotomy at the University of Michigan Hospitals were randomized to receive either external pneumatic compression (EPC) or antiembolism gradient elastic stockings (ANTI-EM, JOBST Institute, Inc., Toledo, Ohio). Prior to randomization, informed consent was obtained from each patient according to the regulations of the Human Use Committee at the University of Michigan. After consent was obtained, baseline IPG studies were performed on each lower extremity. Patients were excluded from this study for the following reasons: if they had abnormal preoperative IPGs or a history of DVT or thromboembolism, if they were unable to give their own consent, or if they chose not to participate. Patients were excluded if they had been at bed rest for 48 hours or longer prior to admission to the hospital in an attempt to eliminate those patients harboring silent deep venous thromboses in the preoperative state. Thirty-eight patients received ANTI-EM, whereas 32 patients received EPC. Mechanical prophylaxis was administered after randomization and baseline IPGs and continued not only through the duration of surgery but also postoperatively until the patients were ambulatory. The average length of postoperative prophylaxis was 3 to 7 days (range 3-22 
Table 1. Diagnosis of 70 Randomized Patients Undergoing Craniotomy

\begin{tabular}{lc}
\hline \multicolumn{1}{c}{ Diagnosis } & Number \\
\hline Glioma & 17 \\
Aneurysm & 15 \\
Meningioma & 10 \\
Intractable seizures & 8 \\
Arteriovenous malformation & 5 \\
Pituitary adenoma & 4 \\
Mctastatic neoplasm & 4 \\
Acoustic neuroma & 2 \\
Third ventricular neoplasms & 2 \\
Other & 3 \\
\hline
\end{tabular}

days). Impedance plethysmographic studies were obtained twice in the first week postoperatively unless patients were discharged home prior to postoperative day 7 . The two groups were matched with respect to age, sex, diagnosis, and preoperative risk factors for deep venous thrombosis. Medical conditions were similar between the two groups.

The diagnoses of the patients are listed in Table 1. Brain tumors were the most prevalent finding in the patients studied. Patients with vascular pathology were divided betwecn those with asymptomatic lesions and those with subarachnoid hemorrhage.

The length of operation ranged between $2 \frac{1}{2}$ and $8 \frac{1}{2}$ hours. All patients received general anesthesia.

\section{Results}

Three patients developed abnormal postoperative IPGs (Table 2). Two of the three were asymptomatic; subsequent venography in these two patients was negative (false-positive rate of $2.9 \%$ ). Patient JS had a normal postoperative IPG, however, subsequently developed a pulmonary embolus requiring pulmonary angiography and placement of an inferior vena cava (IVC) filter (false-negative rate of $1.4 \%$ ). Patient EJ developed an abnormal IPG; venography confirmed a DVT. She also underwent placement of an IVC filter.
During the study period, one patient who elected not to participate died of a fatal pulmonary embolus postoperatively. Otherwise, there were no deaths in this patient population.

The overall rate of thromboembolic complications in this study population was $2.9 \%$.

\section{Discussion}

Recent reports regarding the incidence of DVT in neurosurgical patients range between $2.3 \%$ and $43 \%$ $[2,3,7,8,14,19,24,25,27,28]$. Although pulmonary embolism (PE) is more life threatening than DVT, its incidence is lower in this patient population, ranging between $1.8 \%$ and $25 \%[3,20,25]$. The rates vary according to method of prophylaxis, method of detection, and presence of risk factors.

Coon [9] reviewed the epidemiology of venous thromboembolism and identified the following risk factors: surgery, age, heart failure, previous DVT, lower extremity trauma, obesity, use of oral contraceptives, sepsis, malignancy, and limb weakness. Increased duration of the surgical procedure correlated with an increased risk of DVT. Puls et al [20] noted that prolonged patient immobilization was a significant factor in the development of PE in 25\% of neurosurgical patients. Risk factors in patient $\mathrm{EJ}$ included age (65 years), obesity, and length of operation ( $8 \frac{1}{2}$ hours). However, parient JS had only surgery ( $3 \frac{1}{2}$ hours) as a risk factor.

The mechanism of protection from mechanical prophylaxis of DVT appears to involve both local and systemic factors. The antistasis effect of gradient elastic stockings (ANTI-EM) and EPC has been well documented $[4,13,16]$. Elastic support of 16 to $20 \mathrm{~mm} \mathrm{Hg}$ decreases venous stasis and increases venous return, as documented by venography $[13,16]$. Leg wrappings and stockings without a pressure gradient are ineffective in the prevention of DVT in hospitalized patients [6,21].

Significant increases in fibrinolytic activity have been associated with EPC $[1,15,26]$. The period of "fibrino-

Table 2. Data Representing Patients with Abnormal IPGs and Thromboembolic Complications

\begin{tabular}{|c|c|c|c|c|c|c|c|}
\hline Patient & Age & Diagnosis & Prophylaxis & $\begin{array}{l}\text { Length } \\
\text { of surgery }\end{array}$ & $\begin{array}{l}\text { Post-op } \\
\text { IPG }\end{array}$ & Investigation & Treatment \\
\hline JS & 36 & Glioma & Anti-EM & $3 \frac{1}{2} \mathrm{~h}$ & - & $\begin{array}{c}+ \text { Pulmonary } \\
\text { angiogram }\end{array}$ & $\begin{array}{l}\text { IVC } \\
\text { filter }\end{array}$ \\
\hline EJ & 65 & Meningioma & EPC & $8 \frac{1}{2} \mathrm{~h}$ & + & +Venogram & $\begin{array}{l}\text { ICV } \\
\text { filter }\end{array}$ \\
\hline $\mathbf{M N}$ & 42 & Glioma & Anti-EM & $3 \frac{1}{2} \mathrm{~h}$ & + & -Venogram & - \\
\hline CL & 66 & Meningioma & EPC & $4 \frac{1}{2} \mathrm{~h}$ & + & -Venogram & - \\
\hline
\end{tabular}

Abbreviations: Anti-EM, Antiembolism gradient elastic stockings; EPC, external pneumatic compression; IVC, inferior vena cava. 
lytic shutdown" following surgery appears to be reversed with intermittent calf compression perioperatively. Intermittent compression of the arms produces similar effects, further supporting the hypothesis that venous occlusion stimulates the fibrinolytic activity of blood in an occluded limb, an effect that is seen systemically [1].

Pharmacological prophylaxis of DVT has been shown to decrease the incidence of postoperative thromboembolic complications $[8,10,19,22,28]$. Lowdose heparin, aspirin, coumadin, and dextran have been used with varying degrees of success. Cerrato et al [8] compared 50 control patients undergoing craniotomy with 50 patients who received 5000 units of heparin subcutaneously preoperatively and postoperatively and noted a decrease in DVT from $34 \%$ to $6 \%$ as detected by ${ }^{125}$ I-fibrinogen scanning. Moser et al [18] reported that mechanical prophylaxis was as effective as pharmacological prophylaxis in 227 patients receiving either heparin, heparin and dihydroergotamine, or EPC plus physiotherapy. Recent reports of pharmacological prophylaxis combined with antistasis devices greatly reduced the incidence of postoperative DVT $[4,17]$.

The timing of prophylaxis remains controversial. Bynke et al [7] reported using EPC intraoperatively only on 31 patients undergoing craniotomy and found that there was no need to extend the treatment beyond the operating room. In the current report, mechanical prophylaxis was begun preoperatively and continued intraoperatively and postoperatively.

Although many methods of detection of DVT exist, IPG was used in this clinical trial because it has been shown to be both noninvasive and highly reliable, especially with serial testings $[11,12]$. The false-positive rate of $2.0 \%$ and false-negative rate of $1.4 \%$ obtained in this trial support the clinical utility of IPG.

Patients undergoing high-risk operations such as craniotomy are exposed to a higher risk of DVT $[5,27,28]$. Reports of DVT as high as $34 \%$ in control groups undergoing craniotomy and receiving no prophylaxis [8] are unacceptable and precluded the use of a control group in this clinical trial. Similarly, patients with a prior history of DVT and those placed at bed rest longer than 48 hours prior to randomization were excluded to avoid experimental basis.

The incidence of thromboembolic complications in this study was $2.9 \%$, which is comparable to recent reports of mechanical prophylaxis in neurosurgical patients $[2,3,7,24,27]$. There was no difference in those patients treated with ANTI-EM versus those treated with EPC. Both methods are safe and reliable and can be used throughout the perioperative period without the potential risk of hemorrhage that exists with ccrtain anticoagulants. The authors recommend mechanical prophylaxis of DVT in neurosurgical practice, especially in patients undergoing craniotomy.

This study was partially supported by the JOBST Institute, Inc., of Toledo, Ohio. The authors are grateful to Ms. Yvonne Jones for her skillful preparation of the manuscript.

\section{References}

1. Allenby F, Boardman L, Pflug JJ, Clanan JS. Effects of external pneumatic intermittent compression on fibrinolysis in man. Lancet 1973;2:1412-4.

2. Becker DM, Gonzalez J, Gentili A, Eismont F, Green BA. Prevention of deep venous thrombosis in patients with acute spinal cord injuries: use of rotating treatment tables. Neurosurgery 1987;20:675-7.

3. Black PMcL, Baker MF, Snook CP. Experience with external pneumatic calf compression in neurology and neurosurgery. Neurosurgery 1986;18:440-4.

4. Borow M, Goldson JR. Prevention of postoperative deep venous thrombosis and pulmonary emboli with combined modalities. Am Surg 1983;49:599-605.

5. Brisman R, Mendell J. Thromboembolism and brain tumors. J Neurosurg 1973:38:337-8

6. Browse NL, Jackson BT, Mayo ME, Negus D. The value of mechanical methods of preventing postoperative calf vein thrombosis. Br J Surg 1974;61:219-23.

7. Bynke O, Hillman J, Lassvik C. Does preoperative external pneumatic leg muscle compression prevent postoperative venous thrombosis in neurosurgery? Acta Neurochir 1987;88:46-8.

8. Cerrato D, Ariano C, Fiacchino F. Deep vein thrombosis and low-dose heparin prophylaxis in neurosurgical patients. J Neurosurg 1978;49:378-81.

9. Coon WW. Epidemiology of venous thromboembolism. Ann Surg 1977;186:149-64.

10. Gallus AS, Hirsh J, Tuttle RJ, Trebilcock R, O'Brien SE, Carrol JJ, Minden JH, Hudecki SM. Small subcutaneous doses of heparin in prevention of venous thrombosis. N Engl J Med 1973;288:545-51.

11. Hull RD, Hirsh J, Carter CJ, Jay RM, Ockelford PA, Buller HR, Turpie AG, Powers P, Kinch D, Dodd PF, Gill GH, Leclerc JR, Gent M. Diagnostic efficacy of impedance plethysmography for clinically suspected deep-vein thrombosis. A randomized trial. Ann Intern Med 1985;102:21-8.

12. Hull R, Hirsh J, Sackett DL, Taylor DW, Carter C, Turpie AG, Zielinsky A, Powers P, Gent M. Replacement of venography in suspected venous thrombosis invasive approach. Ann Intern Med $1981 ; 94: 12-5$.

13. Husni EA, Ximenes JOC, Guyette EM. Elastic support of the lower limbs in hospital patients. A critical study. JAMA 1970;214:1456-62.

14. Joffe SN. Incidence of postoperative deep vein thrombosis in neurosurgical patients. J Neurosurg 1975;42:201-3.

15. Knight MTN, Dawson R. Effect of intermittent compression of the arms on deep venous thrombosis in the legs. Lancet 1976;2:1265-8.

16. Lewis CE, Antoine J, Mueller C, Talbot WA, Swaroop S, Edwards WS. Elastic compression in the prevention of venous stasis. A critical reevaluation. Am J Surg 1976;132:739-43.

17. Merli GJ, Herbison GJ, Diteunno JF, Weitz HH, Hewnzes JH, Park CH, Jaweed MM, Heltzel J. Deep venous thrombosis: prophylaxis in acute spinal cord injured patients. Arch Phys Med Rehabil 1988;69:661-4 
18. Moser G, Krahenbuhl B, Barroussel R, Bene JJ, Donath A, Rohner A. Mechanical versus pharmacologic prevention of deep venous thrombosis. Surg Gynecol Obstet 1981;152:448-50.

19. Powers SK, Edwards MSB. Prophylaxis of thromboembolism in the neurosurgical patient: a review. Neurosurgery 1982;10:50913.

20. Puls M, Horst HM, Diaz FG. Neurosurgical patients: at high risk for pulmonary emboli. Surg Forum 1986;37:522-3.

21. Rosengarten DS, Laird J, Jeyasingh $\mathrm{K}$, Martin $\mathrm{P}$. The failure of compression stockings (Tubigrip) to prevent deep venous thrombosis after operation. Br J Surg 1970;57:296-9.

22. Salzman EW, Davies GC. Prophylaxis of venous thromboembolism. Analysis of cost-effectiveness. Ann Surg 1980;191:207-18.

23. Sautter RD, Larson DE, Bhattacharyya SK, Chen HM, Treuhaft PS, Millbauer JP, Mazza JJ, Emanuel DA, Koch EL, Lolley DM, Myers WO, Ray JF, Plotka ED, Nyez GR, Wenzel FJ. The limited utility of fibrinogen I 125 leg scanning. Arch Intern Med 1979;139:148-53
24. Skillman JJ, Collins REC, Coe NP, Goldstein BS, Shapiro RM, Zervas NT, Bettman MA, Salzman EW. Prevention of deep vein thrombosis in neurosurgical patients: a controlled randomized trial of external pneumatic compression boots. Surgery 1978;83:354-8.

25. Swann KW, Black PMcL. Deep vein thrombosis and pulmonary emboli in neurosurgical patients: a review. J Neurosurg 1984;61:1055-62.

26. Tarnay TJ, Rohr PR, Davidson AG, Stevenson MM, Byars EF, Hopkins GR. Pneumatic calf compression, fibrinolysis, and the prevention of deep venous thrombosis. Surgery 1980;88:48995.

27. Turpie AGG, Gallus AS, Beattie WS, Hirsh J. Prevention of venous thrombosis in patients with intracranial disease by intermittent pneumatic compression of the calf. Neurology $1977 ; 27: 435-8$

28. Valladares JB, Hankinson JH. Incidence of lower extremity deep vein thrombosis in neurosurgical patients. Neurosurgery 1980;6:138-41. 